\title{
Letter
}

\section{Characterizing the surge behavior of Alakesayi Glacier in the West Kunlun Shan, Northwestern Tibetan Plateau, from remote-sensing data between 2013 and 2018}

\section{INTRODUCTION}

Surge-type glaciers experience well-defined cyclical nonsteady flow, with alternation between short active phases (months-years) characterized by rapid terminus advance, and longer quiescent phases (years-decades) characterized by terminus stagnation or retreat (Meier and Post, 1969; Copland and others, 2011). Glacier surges can cause disasters, such as the 2002 Kolka glacier catastrophe in the Caucasus, which killed more than 100 people (Kotlyakov and others, 2004), the largest recorded glacial-lake outburst flood events in historical time caused by 1986 and 2002 surges of Hubbard Glacier (Motyka and Truffer, 2007), and the 2015 surge and avalanche of Karayaylak Glacier, which swallowed 1000 ha of grazing meadow and damaged over 61 herdsmen's houses (Lv and others, 2016; Shangguan and others, 2016). Although glacier surging has been recognized by scientists since the earliest study of Alaska glacier surges during the 1890s, the mechanism of surging remains poorly understood (Guo and others, 2013); thus, identification and study of glacier surge helps not only to understand the mechanics of glacier surging but also to protect human life and property.

High Mountain Asia (HMA) hosts the largest glacier concentration outside the polar regions. In HMA, some glaciers surging in the Karakoram and West Kunlun regions have been identified by satellite remote sensing (Copland and others, 2011; Yasuda and Furuya, 2013, 2015; Quincey and others, 2015; Bhambri and others, 2017; Usman and Furuya, 2018; Chudley and Willis, 2019), but comprehensive study of surge behaviors in this area is still limited. In this letter, by utilizing remotesensing data, we are able to estimate and present the changes in surface velocity, terminus, morphological features and glacier thickness of Alakesayi Glacier during its recent surge and thus expand the knowledge of Alakesayi Glacier surge dynamics.

Alakesayi Glacier (N 35 21'52"; E 81 29'43", GLIMS ID: G081483E35351N) is in the eastern part of the West Kunlun Shan (WKS), northwestern Tibetan Plateau, China (Fig. 1), which is one of the regions with the most densely concentrated mountain glaciers in the Tibetan Plateau. The glacier is $18.5 \mathrm{~km}$ long and covers an area of $92.82 \mathrm{~km}^{2}$. It flows northward from an elevation of $6786 \mathrm{~m}$ a.s.l. and terminates at $5280 \mathrm{~m}$ a.s.l., with a snowline elevation of $5740 \mathrm{~m}$ a. s.l.. Previous studies have shown that Alakesayi Glacier flowed at relatively low speed of $\sim 0.1 \mathrm{md}^{-1}$ during 200609 (Yasuda and Furuya, 2013; Yan and others, 2015), and its terminus retreated from the 1970s until about 2000 when it may have slightly advanced (Yasuda and Furuya, 2015).

\section{METHODS}

We derived glacier surface velocity from Landsat $8 \mathrm{OLI}$ images, which have been extensively used to estimate glacier velocities (Fahnestock and others, 2016; Lv and others, 2016; Paul and others, 2017). Sixteen images in the same path/row (Path 145, Row 035) were chosen and downloaded from the website of the USGS (https://earthexplorer. usgs.gov/). Image correlation algorithm in the frequency domain implemented in Cosi-corr (Co-registration of Optically Sensed Images and Correlation) software package (Leprince and others, 2007) was used to estimate the glacier surface displacement measurements because this algorithm has already been proven to obtain accurate results (Leprince and others, 2007; Herman and others, 2011). We used an initial search window of $128 \times 128$ pixels and a $32 \times 32$-pixel window as the final window, which was obtained empirically after extensive testing. The threshold of the signal-to-noise ratio was set to 0.95 to avoid the occurrence of a correlation bias, and four robustness iterations were applied. We set the step size to 8 pixels to produce velocity maps with $120 \mathrm{~m}$ resolution. The correlating results were first filtered by a median low-pass filter, velocity vector fields were then inspected visually and any remaining anomalous vectors were manually removed. Finally, the vector fields were scaled into units of $\mathrm{m} \mathrm{d}^{-1}$ to be comparable with each other. The uncertainty is obtained by measuring displacement in the off-glacier area and was smaller than $8 \mathrm{~m}$ for each Landsat-derived displacement map with a time span of 16-96 days, which is consistent with previous studies (Dehecq and others, 2015; Kääb and others, 2016).

The glacier terminus fluctuations were measured manually at $\sim 1$-year intervals. Because the Landsat 8 images were well co-registered within subpixel, the accuracy of terminus advance was considered to be within $30 \mathrm{~m}$. Surface morphological features were also interpreted visually from remote-sensing images.

The change in surface elevation during the surge can be estimated by the DEM difference method (Round and others, 2017; Wendt and others, 2017).We adopted the Shuttle Radar Topography Mission (SRTM) 1 arc-second DEM and Advanced Spaceborne Thermal Emission and Reflection Radiometer (ASTER) DEM to evaluate the surface elevation changes. The SRTM DEM was acquired in February 2000 and ASTER DEMs were acquired on on 5 December 2012 and 28 January 2018, respectively. Before DEM differencing, the quality of ASTER DEMs was checked using the SRTM DEM. The ASTER DEMs were first co-registered to the SRTM DEM using the method proposed by Nuth and Kääb (2011) and then evaluated by calculating the difference between ASTER DEMs and the SRTM DEM in off-glacier area. The standard deviations in off-glacier area were $5.3 \mathrm{~m}$ and $6.1 \mathrm{~m}$ for the ASTER DEM of 5 December 2012 and 28 January 2018, respectively, which proved the usability of ASTER DEMs to quantify the glacier elevation change of Alakesayi Glacier. Then, the ASTER DEM of 28 January 2018 was co-registered to that of 5 December 2012, with a standard deviation of $7.1 \mathrm{~m}$, to 


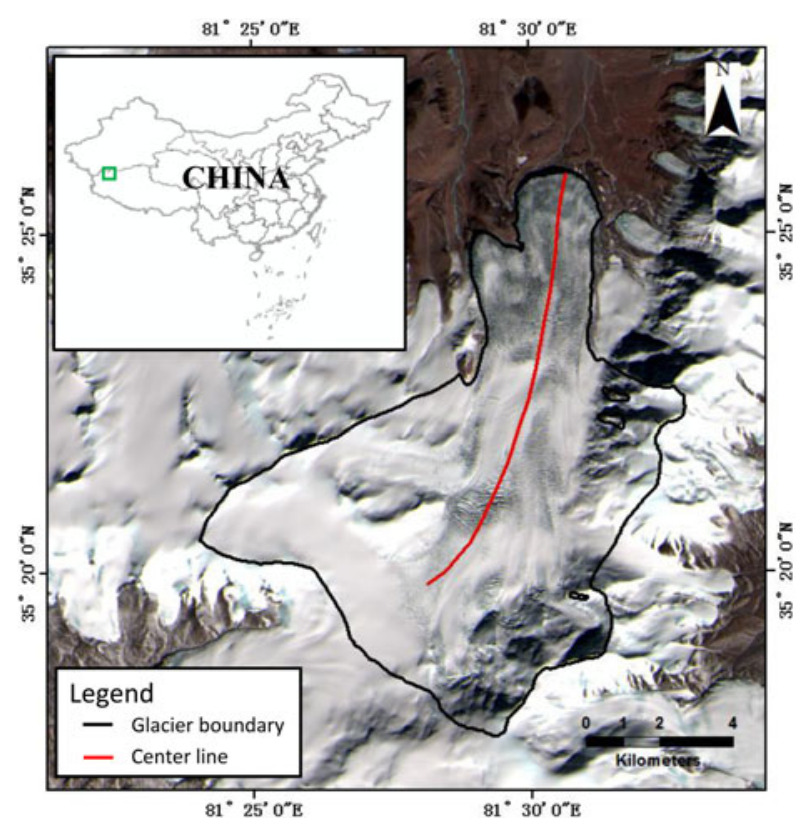

Fig. 1. Landsat 8 scene of Alakesayi Glacier on 15 November 2017, with glacier outline (black) and manually delineated center line (red). The green rectangle in the inset indicates the location of Alakesayi Glacier in China.

quantify the elevation change between 5 December 2012 and 28 January 2018. The differencing maps were filtered by a $3 \times 3$ low-pass filter to produce smoothing results and some visual artefacts in the accumulation area induced by clouds and snow cover were removed since optical images have poor textures due to the saturation in the snowcovered regions.

\section{RESULTS}

We derived eight surface velocity maps at different surge times, as displayed in Figure 2. Profiles were extracted from these velocity maps using the manually delineated center line shown in Figure 1 to provide some insight into the evolution of glacier surge. An increasing trend and a decreasing trend in velocity can be seen clearly in Figure $3 a$ and b, respectively. In Figure 3a, the velocity between 11 September 2013 and 16 December 2013 was $\sim 0.3 \mathrm{md}^{-1}$, which was three times the velocity of $\sim 0.1 \mathrm{~m} \mathrm{~d}^{-1}$ in previous studies (Yasuda and Furuya, 2013; Yan and others, 2015), meaning that the glacier may have been in the pre-surge phase. Velocity then increased slowly, reaching $\sim 1.5 \mathrm{~m} \mathrm{~d}^{-1}$ in the time span of 1 November 2014 to 3 December 2014. After this time, the velocity increased rapidly until it reached a peak between 3 October 2015 and 4 November 2015 with a magnitude of $\sim 4.5 \mathrm{~m} \mathrm{~d}^{-1}$, which is an order of magnitude greater than the velocity in 2006-09 (Yasuda and Furuya, 2013; Yan and others, 2015). The glacier then decelerated until the period between 8 December 2016 and 10 February 2017 (Fig. 3b). From 8 December 2016, the velocity decreased more slowly until 28 January 2018 when it reached almost below $0.5 \mathrm{~m} \mathrm{~d}^{-1}$ (Fig. 3b). A surge front could be identified at different surge stages, and it moved towards the glacier terminus as the surge continued.

The dynamics of the glacier terminus can be revealed by the lengths of the red lines shown in Figure 4. From 16 December 2013 to 3 December 2014, the glacier advanced
$29 \mathrm{~m}$ (Fig. 4a and b), which is consistent with the low surface velocity speed at this time. During 3 December 2014 and 6 December 2016 when the surface velocity was higher, the terminus moved forward rapidly over distance of $641 \mathrm{~m}$ for the period from 3 December 2014 to 6 December 2015 and $512 \mathrm{~m}$ from 6 December 2015 to 8 December 2016 (Fig. 4b, c and d). The terminus advance reduced to $93 \mathrm{~m}$ from 8 December 2016 to 25 November 2017 (Fig. 4d and f), which agrees well with the velocity decrease during this period.

In WKS, the glaciers are almost free of debris and with clean ice (Scherler and others, 2011) which is also true for Alakesayi Glacier. In winter of 2013 and 2014, crevasses appeared only at the terminus of the Alakesayi Glacier, and most of the Alakesayi Glacier surface was still covered by snow and clean ice, which showed a white color in the images (Fig. 4a and b). From 3 December 2014 to 6 December 2015, as the velocity increased rapidly, the formerly smooth surface began to be broken by crevasses and fractures (Fig. 4b and c), and by 8 December 2016, the glacier surface was almost covered by such features as shown in Figure 4d. A detailed comparison of glacier surfaces between 16 December 2013 and 8 December 2016 can be seen in Figure $4 \mathrm{f}$ and $\mathrm{g}$. The relative absence of fresh crevasses on the glacier surface on 25 November 2017 (Fig. 4e) implied that the rate of glacier flow was much reduced, which can also be confirmed from the velocity data during this period.

The DEM differencing results are shown in Figure $5 a$ and b, respectively. The center line profiles extracted from the two DEM differencing results are shown in Figure 5c. The profile of DEM difference between the SRTM DEM and the DEM of 5 December 2012 shows that there was a slight increase in glacier surface elevation, which is consistent with previous study of mass balance in West Kunlun Shan (Lin and others, 2017). The profile of DEM difference between 5 December 2012 and 28 January 2018 indicates that the surface elevation at $0-4 \mathrm{~km}$ from the terminus had increased, with a maximum increase exceeding $150 \mathrm{~m}$, while the surface elevation at the upper part of the glacier had decreased in the region up-glacier of the $8 \mathrm{~km}$ mark from the terminus.

\section{DISCUSSION AND CONCLUSION}

In this letter, remote-sensing data were utilized to characterize the surge behaviors of Alakesayi Glacier from 2013 to 2018. Glacier surface velocities at different stages were estimated by the image correlation algorithm, and changes in glacier surface elevation were extracted by the DEM differencing method; terminus and surface morphological features were also measured and interpreted visually from remotesensing images. Although the exact timing of the initiation and termination of the surge remains uncertain, our results show that the surge lasted at least 4 years from 11 September 2013 to 28 January 2018. During 3 December 2014 to 8 December 2016, the ice flowed at a velocity of order of magnitude greater than that of 2006-09 (Yasuda and Furuya, 2013; Yan and others, 2015); the terminus advanced $1153 \mathrm{~m}$, and crevasses and fractures formed by dramatic fluctuations in glacier velocity were clearly visible on the glacier surface. The rapid flow of ice, the advance of the terminus and the rapid formation of morphological features suggested that active phase spanned $\sim 2$ years from 3 

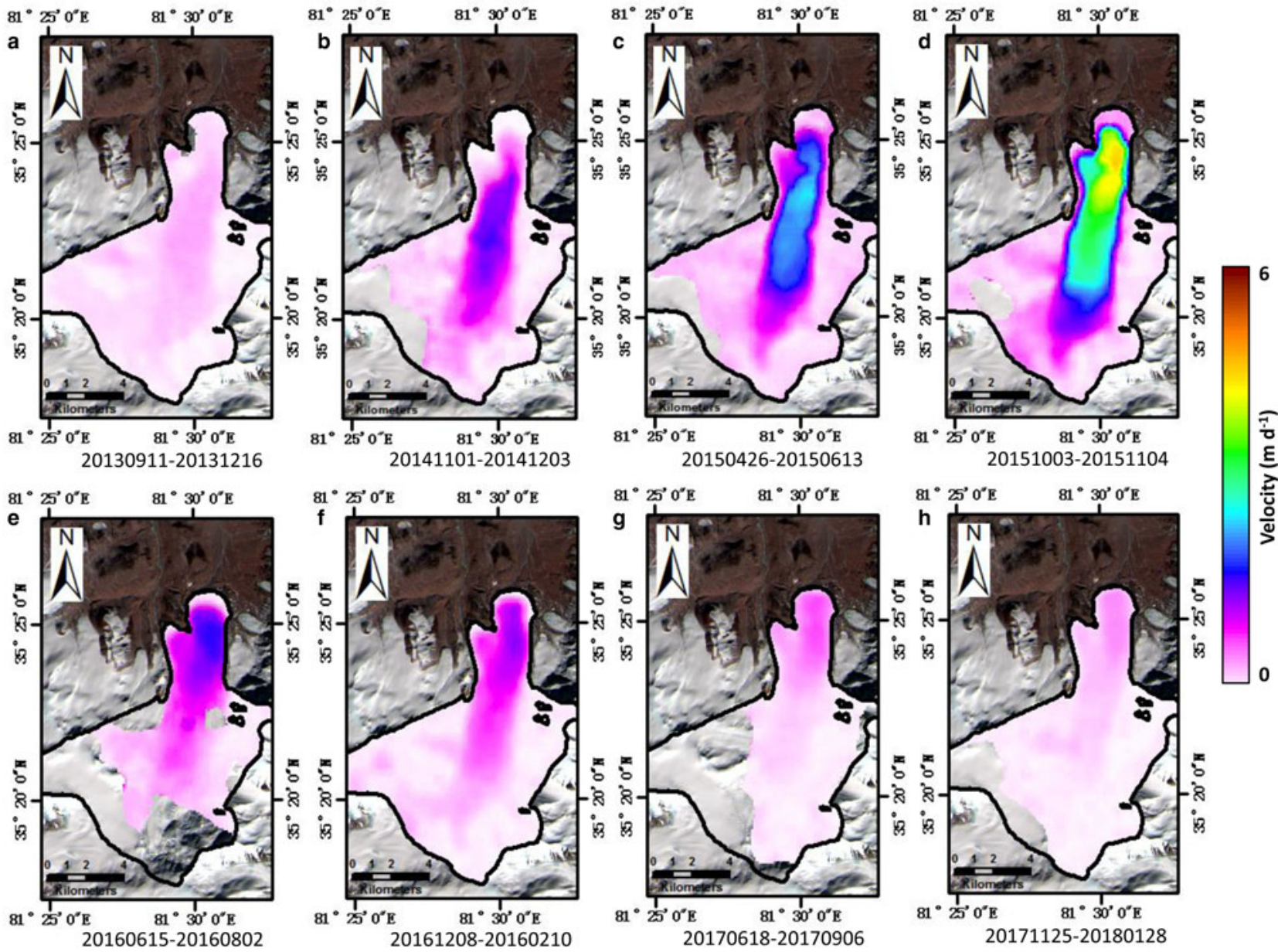

Fig. 2. Velocity maps derived from Landsat image correlation between 11 September 2013 and 1 January 2018. Panels (a)-(h) correspond to 1-3-month intervals indicated by the dates.

December 2014 to 8 December 2016. From the maximum flow velocity of $\sim 4.5 \mathrm{~m} \mathrm{~d}^{-1}$ and recurrence interval of several decades it is not clear whether the surges of Alakesayi Glacier are of Svalbard-type with thermal regulation (Murray and others, 2003), as is suggested for other surge-type glaciers in this region (Yasuda and Furuya, 2015). The active phase of $\sim 2$ years is shorter than the surge phase duration of more than 5 years in other surgetype glaciers in the region. Moreover, no obvious seasonal modulation in surface velocities was observed in Alakesayi Glacier, which may partly be due to the shorter active phase of 2 years and relatively low temporal velocity observations. The DEM differencing results show a thickening of the receiving zone up to $\sim 150 \mathrm{~m}$, and a thinning of the upstream reservoir zone. These surge behaviors revealed by remote-sensing data provide useful insight into the Alakesayi Glacier surge dynamics and will be of interest for the research of glacier mass balance in this area.
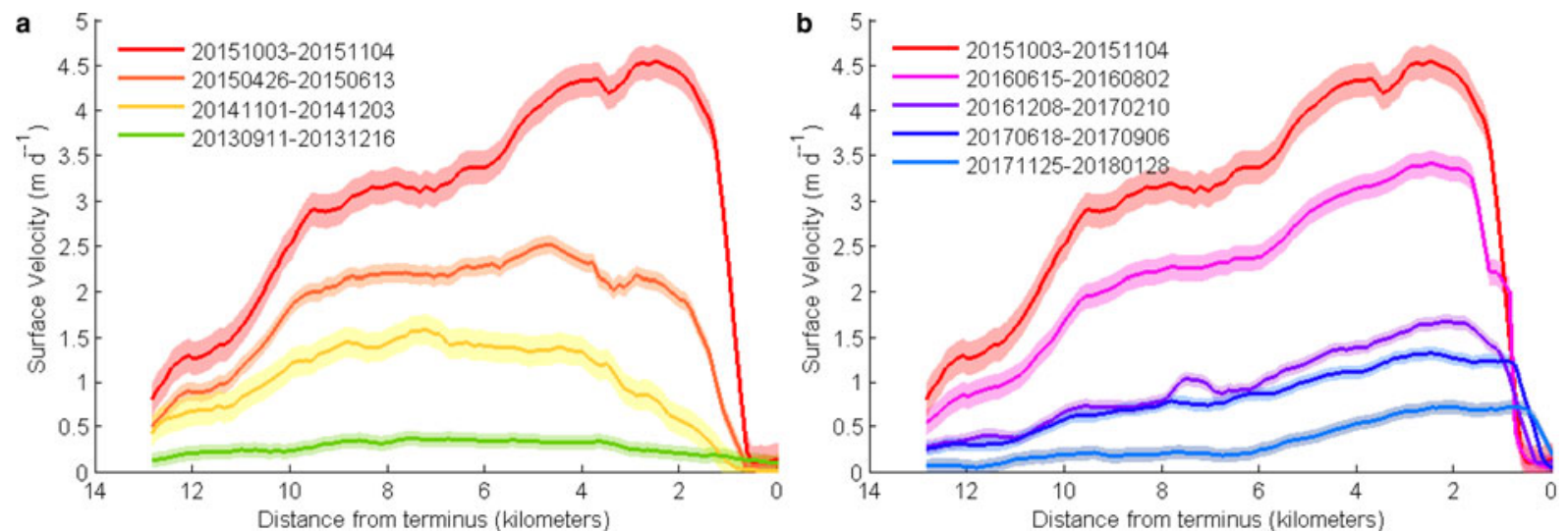

Fig. 3. Center velocity lines extracted from the eight velocity maps in Figure 2. (a) Center line velocity profiles between 11 September 2013 and 4 November 2015; (b) Center line velocity profiles between 3 October 2015 and 28 January 2018. Shading envelopes represent the errors in velocity measurements. Note that profile 20151003-20151104 is shown in both panels. 

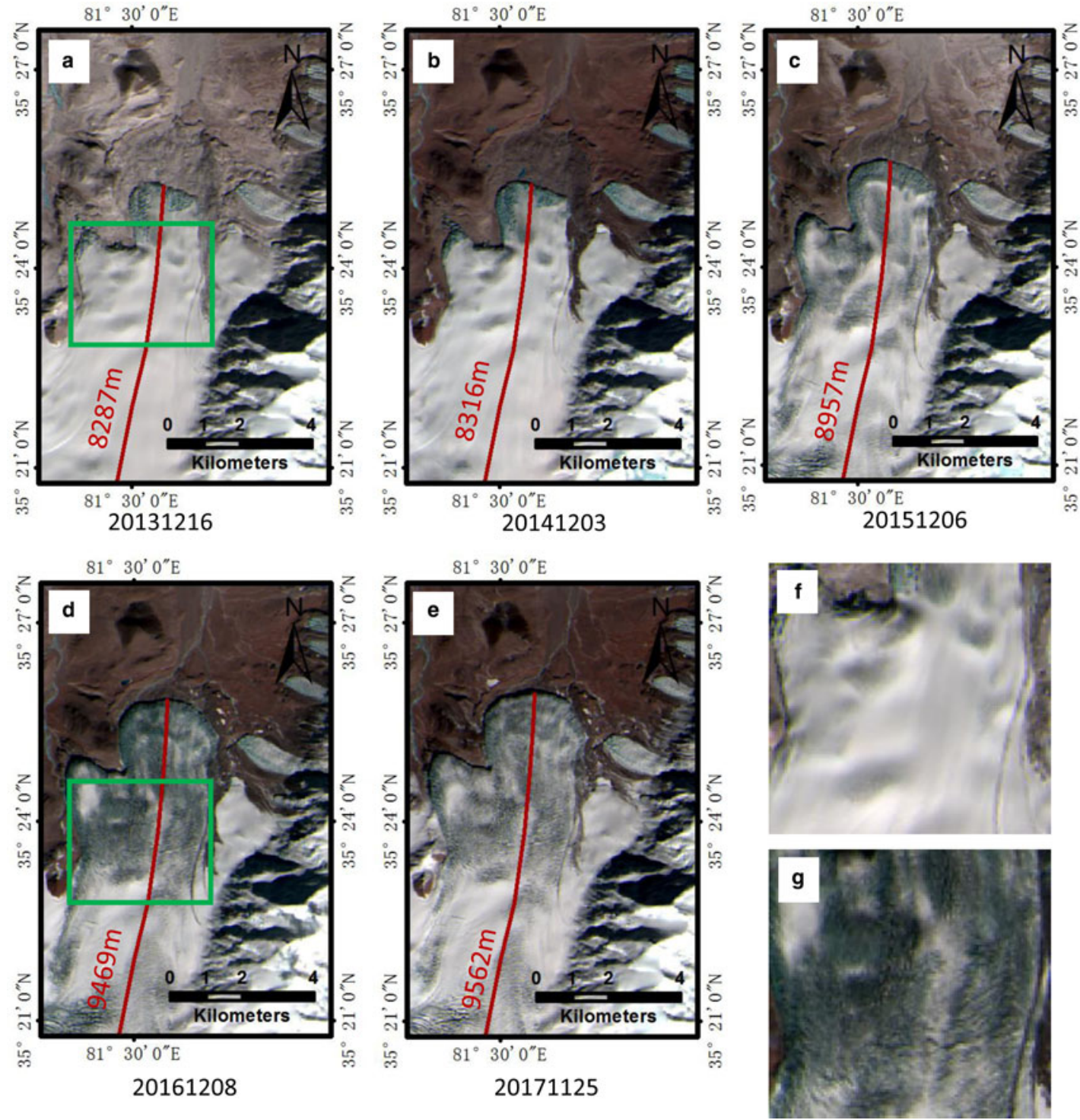

Fig. 4. Changes in the glacier terminus and morphological features from 16 December 2013 to 25 November 2017. (a)-(e) correspond to changes of glacier terminus and morphological features. ( $\mathrm{f}$ ) is an enlargement of the green box in (a), and (g) is an enlargement of the green box in $(d)$.
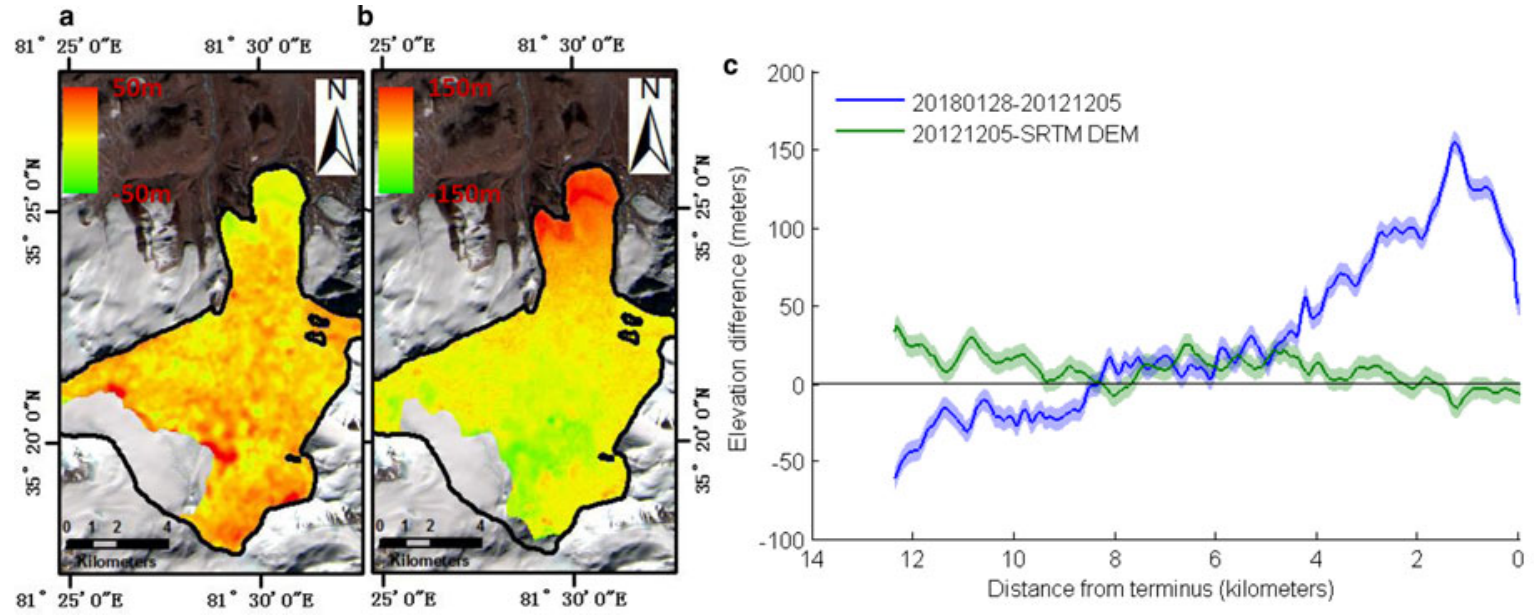

Fig. 5. DEM differencing results of Alakesayi Glacier. (a) DEM differencing results of 5 December 2012 and SRTM DEM. (b) DEM differencing results for 28 January 2018 and 5 December 2012. (c) Center line profiles extracted from two DEM differencing results; the light color shadings represent the errors in DEM differencing results. Note that the scale of the color bar is different between (a) and (b). 


\section{ACKNOWLEDGMENTS}

This work was supported in part by the National Key Research and Development Program of China (grant numbers 2016YFB0501501, and 2016YFA0600304), the National Natural Science Foundation of China (grant numbers 41471066 and 41471065), and the International Partnership Program of Chinese Academy of Sciences (grant number 131C11KYSB20160061). We greatly appreciate the Editor and the anonymous reviewers for their constructive and valuable comments.

${ }^{1}$ Key Laboratory of Digital Earth Science, Institute of Remote Sensing and Digital, Earth, Chinese Academy of JIANMIN ZHOU ${ }^{1}$ Sciences, Beijing 100094, China

${ }^{2}$ University of Chinese Academy of Sciences, Beijing 100049, China

E-mail: Jianmin Zhou <zhoujm@radi.ac.cn>

\section{REFERENCES}

Bhambri R, Hewitt K, Kawishwar P and Pratap B (2017) Surge-type and surge-modified glaciers in the Karakoram. Sci. Rep., 7, 15391 (doi: 10.1038/s41598-017-15473-8)

Chudley TR and Willis IC (2019) Glacier surges in the north-west West Kunlun Shan inferred from 1972 to 2017 Landsat imagery. J. Glaciol., 65(249), 1-12 (doi: 10.1017/jog.2018.94).

Copland L and 7 others (2011) Expanded and recently increased glacier surging in the Karakoram. Arct. Antarct. Alp. Res., 43 (4), 503-516 (doi: 10.1657/1938-4246-43.4.503)

Dehecq A, Gourmelen N and Trouve E (2015) Deriving large-scale glacier velocities from a complete satellite archive: application to the Pamir-Karakoram-Himalaya. Remote Sens. Environ., 162, 55-66 (doi: 10.1016/j.rse.2015.01.031)

Fahnestock M and 5 others (2016) Rapid large-area mapping of ice flow using Landsat 8. Remote Sens. Environ., 185, 84-94 (doi: 10.1016/j.rse.2015.11.023)

Guo W, Liu S, Wei J and Bao W (2013) The 2008/09 surge of central Yulinchuan glacier, northern Tibetan Plateau, as monitored by remote sensing. Ann. Glaciol., 54(63), 299-310 (doi: 10.3189/ 2013AoG63A495)

Herman F, Anderson B and Leprince S (2011) Mountain glacier velocity variation during a retreat/advance cycle quantified using sub-pixel analysis of ASTER images. J. Glaciol., 57(202), 197207 (doi: 10.3189/002214311796405942)

Kääb A and 5 others (2016) Glacier remote sensing using Sentinel-2. Part I: radiometric and geometric performance, and application to ice velocity. Remote Sens., 8(7), 598 (doi: 10.3390/rs8070598)

Kotlyakov VM, Rototaeva O and Nosenko G (2004) The September 2002 Kolka glacier catastrophe in North Ossetia, Russian Federation: evidence and analysis. Mt. Res. Dev., 24(1), 78-83 (doi: 10.1659/0276-4741(2004)024[0078:TSKGCI]2.0.CO;2)

Leprince S, Barbot S, Ayoub F and Avouac J (2007) Automatic and precise orthorectification, coregistration, and subpixel correlation of satellite images, application to ground deformation measurements. IEEE Trans. Geosci. Remote Sens., 45(6), 1529-1558 (doi: 10.1109/TGRS.2006.888937)

Lin H, Li G, Cuo L, Hooper A and Ye Q (2017) A decreasing glacier mass balance gradient from the edge of the Upper Tarim basin to the Karakoram during 2000-2014. Sci. Rep., 7(1), 6712 (doi: 10.1038/s41598-017-07133-8).

Lv $\mathrm{M}$ and 7 others (2016) A rapid glacier surge on Mount Tobe Feng, western China, 2015. J. Glaciol., 62(232), 407-409 (doi: 10.1017/jog.2016.42)

Meier MF and Post A (1969) What are glacier surges? Can. J. Earth Sci., 6(4), 807-817 (doi: 10.1139/e69-081)

Motyka RJ and Truffer M (2007) Hubbard Glacier, Alaska: 2002 closure and outburst of Russell Fjord and postflood conditions at Gilbert Point. J. Geophys. Res.-Earth Surf., 112(F2), F02004 (doi: 10.1029/2006JF000475)

Murray T, Strozzi T, Luckman A, Jiskoot H and Christakos P (2003) Is there a single surge mechanism? Contrasts in dynamics between glacier surges in Svalbard and other regions. J. Geophys. Res.Solid Earth, 108(B5), 2237 (doi: 10.1029/2002JB001906)

Nuth C and Kääb A (2011) Co-registration and bias corrections of satellite elevation data sets for quantifying glacier thickness change. Cryosphere, 5(1), 271-290 (doi: 10.5194/tc-5-2712011)

Paul F, Strozzi T, Schellenberger T and Kääb A (2017) The 2015 surge of Hispar Glacier in the Karakoram. Remote Sens., 9(9), 888 (doi: 10.3390/rs9090888)

Quincey DJ, Glasser NF, Cook SJ and Luckman A (2015) Heterogeneity in Karakoram glacier surges. J. Geophys. Res.Earth Surf., 120(7), 1288-1300 (doi: 10.1002/2015JF003515)

Round V, Leinss S, Huss M, Haemmig C and Hajnsek I (2017) Surge dynamics and lake outbursts of Kyagar Glacier, Karakoram. Cryosphere, 11(2), 723-739 (doi: 10.5194/tc-11-723-2017)

Scherler D, Bookhagen B and Strecker MR (2011) Spatially variable response of Himalayan glaciers to climate change affected by debris cover. Nat. Geosci., 4(3), 156 (doi: 10.1038/ngeo1068).

Shangguan D and 6 others (2016) Characterizing the May 2015 Karayaylak Glacier surge in the eastern Pamir Plateau using remote sensing. J. Glaciol., 62(235), 944-953 (doi: 10.1017/ jog.2016.81)

Usman M and Furuya M (2018) Interannual modulation of seasonal glacial velocity variations in the Eastern Karakoram detected by ALOS-1/2 data. J. Glaciol., 64(245), 465-476 (doi: 10.1017/ jog.2018.39)

Wendt A, Mayer C, Lambrecht A and Floricioiu D (2017) A Glacier surge of Bivachny Glacier, Pamir Mountains, observed by a time series of high-resolution digital elevation models and glacier velocities. Remote Sens., 9(4), 388 (doi: 10.3390/rs9040388)

Yan S, Liu G, Wang Y, Perski Z and Ruan Z (2015) Glacier surface motion pattern in the Eastern part of West Kunlun Shan estimation using pixel-tracking with PALSAR imagery. Environ. Earth Sci., 74(3), 1871-1881 (doi: 10.1007/s12665-015-4645-7)

Yasuda T and Furuya M (2013) Short-term glacier velocity changes at West Kunlun Shan, Northwest Tibet, detected by Synthetic Aperture Radar data. Remote Sens. Environ., 128, 87-106 (doi: 10.1016/j.rse.2012.09.021)

Yasuda T and Furuya M (2015) Dynamics of surge-type glaciers in West Kunlun Shan, Northwestern Tibet. J. Geophys. Res.-Earth Surf., 120(11), 2393-2405 (doi: 10.1002/2015JF003511) 